\title{
Correspondence
}

To the Editors

\section{Covid-19 pandemic and our paediatric population - the challenges and outcome: an observational study from Eastern India}

Sri Lanka Journal of Child Health, 2020; 49(4): 417-418

DOI: http://dx.doi.org/10.4038/sljch.v49i4.9285

(Key words: Covid-19 pandemic, children, Eastern India, challenges)

\section{Introduction}

In the wake of the Covid-19 pandemic, among other sectors, the health system has been severely affected $^{1}$. The major thrust was on detecting cases and tracing contacts. The non Covid-19 cases especially ones with chronic ailments faced several challenges. The pandemic and subsequent lockdown brought the economy to a grinding halt ${ }^{2}$. It caused the lack of a regular supply of prescribed drugs and an inability to seek medical help, with subsequent non-compliance, which led to complications of an otherwise stable chronic ailment. We at the paediatric rheumatology department of Vivekananda Institute of Medical Sciences conducted a brief observation of our paediatric rheumatology patients during the early part of the pandemic.

\section{Objectives}

To study the impact of COVID-19 pandemic on the paediatric rheumatology patients.

\section{Method}

Patients were contacted through telephonic calls, video calls, WhatsApp messages/calls or mail. We framed a questionnaire for patients and caregivers, comprising 2 parts:

A) Disease activity

B) Questions pertaining to COVID-19 infection

All paediatric patients registered in the paediatric rheumatology outpatient department (OPD) were enrolled in an observational study from April to August 2020.

\section{Results}

Seventy patients were registered in the paediatric rheumatology OPD but due to a variety of reasons, only 55 ultimately participated in the study. Breakdown of the 55 is shown in Table 1.

Of these 55 patients, 4 (two JIA, one JoAS and one MCTD) had stopped all medications, 2 (one SLE and one JDM) had developed complications, 3 (all JIA) had experienced flares and 2 (both systemic onset JIA) had died (Figure 1). Both children who died were COVID-19 negative. Of the 55 patients 5 met COVID-19 testing criteria. Three were tested, but none were positive.

Table 1: Type of disease $(n=55)$

\begin{tabular}{|l|c|}
\hline \multicolumn{1}{|c|}{ Type of disease } & n \\
\hline Juvenile idiopathic arthritis (JIA) & 25 \\
\hline Systemic lupus erythematosus (SLE) & 17 \\
\hline Periodic fever syndromes & 03 \\
\hline Vasculitis & 02 \\
\hline Mixed connective tissue disease (MCTD) & 02 \\
\hline Juvenile onset ankylosing spondylitis (JoAS) & 02 \\
\hline Reactive arthritis & 02 \\
\hline Juvenile dermatomyositis (JDM) & 01 \\
\hline Complex regional pain syndrome (CRPS) & 01 \\
\hline
\end{tabular}

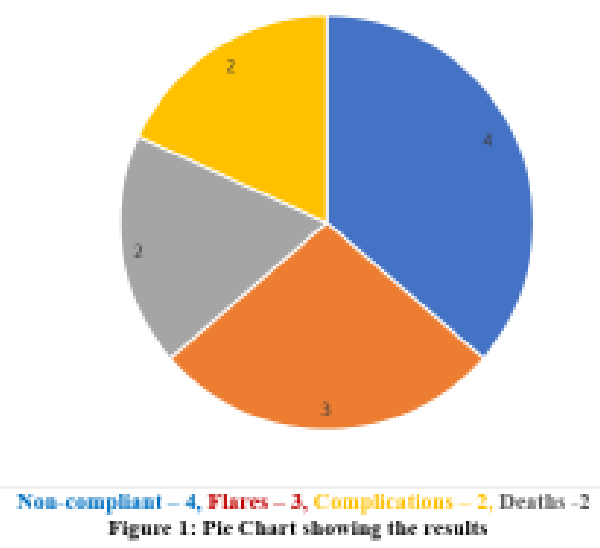

\section{Discussion-}

Our patients are chiefly from outstation and belong to the lower socio-economic group. They mainly rely on the local trains to commute to Kolkata. The pandemic with subsequent lockdown and nonrunning of trains made it almost impossible for them to come to Kolkata for their routine visits and their monthly ration of drugs. Loss of daily wages added to their woes and many found it difficult to continue with their medications. This was compounded by irregular availability of prescribed drugs, especially hydroxychloroquine. However, fortunately some pharmaceutical companies arranged online supply of drugs. One of our systemic onset JIA patients who had a flare did manage to visit us but she had to travel in a private vehicle which did cost her a hefty amount. 
Till now 2 studies using questionnaire have been done which suggest that a substantial proportion of rheumatology patients have experienced changes to their disease management since the emergence of Covid-19,4.

Our study highlights the difficulties which patients with chronic diseases faced in the wake of the pandemic. This study also illustrates the wide gap between urban and rural in the health care system. Such trying times bring to light these lacunae. It raises ethical questions about the plight of patients with chronic diseases accessing health care especially in the rural setting.

\section{References}

1. Kumar A, Nayar KR, Koya FS. COVID19: Challenges and its consequences for rural health care in India. Public Health in Practice 2020; 1: 100009 https://doi.org/10.1016/j.puhip.2020.1000 09

PMCid: PMC7199699

2. Michie J. The covid-19 crisis and the future of the economy and economics. International Review of Applied Economics 2020; 3(34):

https://doi.org/10.1080/02692171.2020.17

56040
3. Gupta L, Misra DP, Agarwal V, Balan S, Agarwal V. Management of rheumatic diseases in the time of Covid -19 pandemic: perspectives of rheumatology practitioners from India. Annals of the Rheumatic Diseases 2020 https://doi.org/10.1101/2020.04.03.200483 89

4. Michaud K, Wipfler K, Shaw Y, Simon TA, Cornish A, England BR, et al. Experiences of patients with rheumatic diseases in the United States during early days of the COVID-19 pandemic. $A C R$ Open Rheumatology2020; 2(6): 335-43. https://doi.org/10.1002/acr2.11148 PMid: 32311836 PMCid: PMC7264613

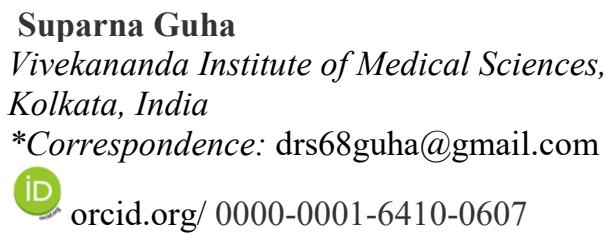

